\title{
The Explanatory Power and the Forecast Performance of Consumer Confidence Indices for Private Consumption Growth in Turkey
}

\author{
Hatice Gökçe Karasoy Can \& Çağlar Yüncüler
}

To cite this article: Hatice Gökçe Karasoy Can \& Çağlar Yüncüler (2018) The Explanatory

Power and the Forecast Performance of Consumer Confidence Indices for Private Consumption Growth in Turkey, Emerging Markets Finance and Trade, 54:9, 2136-2152, DOI: 10.1080/1540496X.2017.1358608

To link to this article: https://doi.org/10.1080/1540496X.2017.1358608

Accepted author version posted online: 10

Aug 2017.

Published online: 19 Apr 2018.

Submit your article to this journal $\pi$

Џ Article views: 63

View Crossmark data \lceil 


\title{
The Explanatory Power and the Forecast Performance of Consumer Confidence Indices for Private Consumption Growth in Turkey
}

\author{
Hatice Gökçe Karasoy $\mathrm{Can}^{1,2}$ and Çağlar Yüncüler ${ }^{1}$ \\ ${ }^{1}$ The Central Bank of the Republic of Turkey, Research and Monetary Policy Department, Ulus/ \\ Ankara, Turkey; ${ }^{2}$ Department of Economics, Bilkent University, Ankara, Turkey
}

\begin{abstract}
In this study, we assess empirically whether consumer confidence indices contain information about future private consumption growth in Turkey. To this end, we estimate models for quarterly total, durable, and nondurable consumption growth with and without sentiment indicators. We evaluate insample forecasts and one-step-ahead out-of-sample forecasts from recursive ordinary least squares (OLS) estimates. We also test permanent income and precautionary savings hypotheses with our results. We use overall indices of CNBC-e and Turkstat-CBRT Surveys, and Consumer Expectations Index (CEI) and Propensity to Consume Index (PCl) from the CNBC-e Survey as sentiment measures. We show that the lagged values of consumer sentiment have explanatory power on consumption growth. However, when used in conjunction with other economic variables such as real labor income, real stock price, real interest rate, and exchange rate, only CNBC-e for total consumption, and CBRT and PCl for nondurable consumption provide independent information about future consumption growth. Similarly, the gains in out-of-sample forecasts are observed under the absence of other variables and disappear in almost all cases following their inclusion to the estimations. Finally, we find no clear evidence for either precautionary savings motive or permanent income hypothesis on the link between consumer sentiment and future total consumption changes.
\end{abstract}

KEY WORDS: consumer confidence, forecasting, private consumption

JEL Classification: C52, C53, D12, E21, E27

Consumption is the largest component of Gross Domestic Product (GDP) in almost all economies and is quite important to understand the course of the economic activity. However, data regarding real economic activity are published with a considerable time lag. Accordingly, timely data, such as consumer confidence indices, become valuable as leading indicators for current and future economic activity. Sentiment surveys have been followed by analysts, policy makers, and forecasters as well as the media because its basic premise is that they contain information about potential changes in consumption (Curtin 2007). Contemporaneous relationship between consumer sentiment and consumption expenditures is hardly surprising (Ludvigson 2004). Low consumer confidence today should restrict the current spending. However, whether they provide information about the future path of consumer spending is an issue that needs to be elaborated.

Mueller (1963), in her pioneering study for the United States (US), proposes that consumer confidence indices may be useful in forecasting private consumption growth when its lagged values are included to the regressions along with the lagged values of consumption growth. Following her, many studies, mostly using the US data, have tested the same argument by introducing other relevant

Address correspondence to Hatice Gökçe Karasoy Can, The Central Bank of the Republic of Turkey, Research and Monetary Policy Department, Anafartalar Mahallesi Istiklal Cad. No.10, 06050 Ulus/Ankara, Turkey. E-mail: gokce.karasoy@tcmb.gov.tr

The views and opinions presented in this study belong to the authors and do not necessarily represent those of the Central Bank of the Republic of Turkey or its staff. 
economic variables (Bram and Ludvigson 1998; Carroll, Fuhrer, and Wilcox 1994; Howrey 2001; Leeper 1992; Ludvigson 2004; Mishkin et al. 1978). As a common finding, consumer sentiment indicators are shown to predict future changes in consumption expenditures; however, the predictive power is limited when they are used in conjunction with other indicators, mostly financial. Studies using real-time data (Croushore 2005; Lahiri, Monokroussos, and Zhao 2012, 2016) did not reach to a clear consensus on the predictive ability of consumer sentiment either. On the other hand, Golinelli and Parigi (2004), Dion (2006), and Dees and Brinca (2013) find that consumer confidence can be an important independent factor in predicting consumption spending in European countries. The studies for developing countries are scarce. Among them, Cuenca, Flores, and Morales (2013) find only marginal effect of consumer confidence on consumption growth in Peru when other economic variables are present.

The predictive power of consumer confidence indices on future consumption growth is also useful in testing economic theories. Carroll, Fuhrer, and Wilcox (1994), Ludvigson (2004), and Lahiri, Monokroussos, and Zhao (2012) test whether their findings for the US can be explained by precautionary savings motive or permanent income hypothesis. They find no clear evidence for any of them with macro-level data. On the other hand, with micro-level data, Souleles (2004) and Cuenca, Flores, and Morales (2013) find evidence to support precautionary savings motive for the US and Peru, respectively.

In this study, we address similar questions for Turkey. It is clear that the quarterly private consumption growth signals a close contemporaneous relationship with the main consumer confidence indices in Turkey (Figure 1). However, we follow the likes of Carroll, Fuhrer, and Wilcox (1994), Bram and Ludvigson (1998), Ludvigson (2004), and Croushore (2005) to determine whether past values of consumer sentiment indicators can help predict future consumption expenditures as well. To this end, we aim to measure explanatory and forecast power of consumer confidence indices on future private consumption growth through three questions: (i) "Does consumer confidence provide information about future private consumption growth?" (ii) "Does consumer confidence provide unique information about future private consumption growth?" (iii) "Does consumer confidence improve out-of-sample forecasts of future private consumption growth?" We think that adopting this approach at first place is useful to form the basis for the literature on this issue in Turkey to progress in a similar fashion to the developed countries. We use four different sentiment indicators to account for consumer sentiment from different aspects. These indicators are the overall indices of CNBC-e and TurksatCBRT (CBRT) surveys and Consumer Expectations Index (CEI) and Propensity to Consume Index (PCI) from the former.

Discretionary purchases can be postponed when sentiment deteriorates (Curtin 2007). As such purchases mostly contain purchases of homes, vehicles, and other household durable goods, we extend our analysis also to durable and nondurable consumption. In addition, we check whether our results
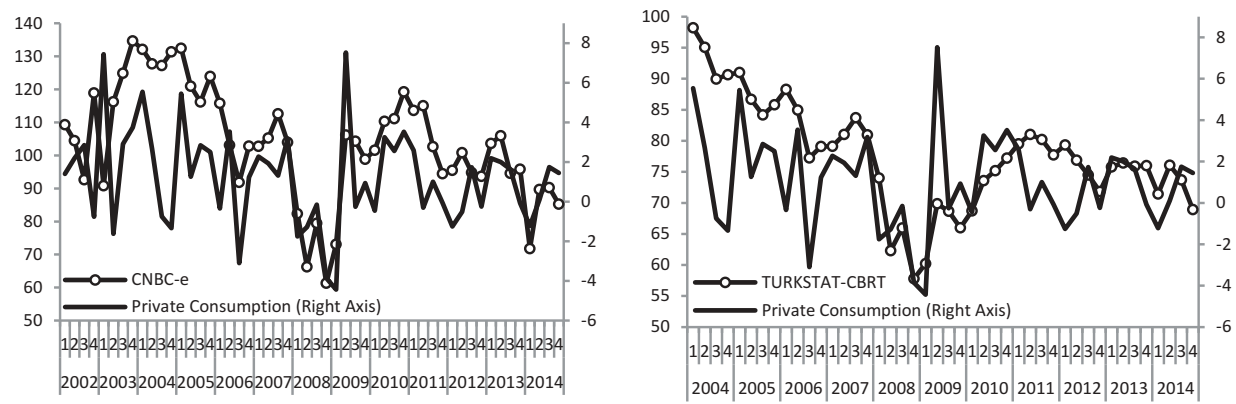

Figure 1. Consumer confidence indices and the growth rate of private consumption. Source: CNBC-e, Turkstat. 
are in parallel with what permanent income hypothesis and precautionary savings motive would suggest for the link between consumer sentiment and next period's consumption growth.

Using the variables in real time is an important issue to consider in short-term forecasting, as revisions in the data, the publication lags, and release dates matter for the policy-making purposes. Diron (2008), Giannone, Reichlin, and Small (2008), and Lahiri, Monokroussos, and Zhao (2016) show examples of pseudo real-time and genuine real-time exercises in GDP forecasts. However, our empirical setup does not necessitate pursuing any type of real-time exercise in our forecasting analysis. The reason has two folds: First, we do not use current period values and use only the lagged values of the explanatory variables in the estimations, contrary to the nowcasting analyses in the aforementioned examples. Furthermore, unlike US and European countries, there are no flash estimates of GDP in Turkey and all data we need at the time of the forecast are already available to the forecaster. We revisit data vintages, release dates, and publication lags in more detail in the data section.

To the best of our best knowledge, this is the first study for Turkey to test the power of consumer confidence on forecasting quarterly private consumption growth empirically and assess it in the light of consumption theories. Previous studies for Turkey have focused mostly on finding either a longterm relationship between consumer confidence and macroeconomic variables or the determinants of consumer confidence. Çelik (2010) shows that movements in the consumer confidence indices are associated with changes in economic and financial variables such as exchange rates, industrial production, and stock exchange index. Moreover, Kandır (2006), Görmüş and Güneş (2010), Çelik, Aslanoğlu, and Uzun (2010), Gürgür and Kılınç (2015), and Karasoy (2015) focus on the relationship between consumer confidence and financial variables. Ceritoğlu (2013) shows that household expectations measured by Consumer Tendency Survey of Turkstat and CBRT have a direct role on consumption and saving decisions. He indicates that expenditure on durables is more sensitive to changes in household expectations. Against this background, we contribute to the limited literature in the developing countries.

We find that the past values of consumer confidence indices have explanatory power on the growth of both total private consumption and its subcomponents, that is, durable and nondurable consumption. However, the power either vanishes or diminishes once we control for real labor income, real stock prices, real interest rate, and exchange rate. CNBC-e for total consumption, and CBRT and PCI for nondurable consumption preserve information about the next period's consumption growth even after controlling for other available economic and financial indicators. Similarly, the gains in out-of-sample forecast over the benchmark models are present in the absence of other variables and disappear in almost all cases following the inclusion of additional explanatory variables to the estimations. Finally, we find that the role of consumer confidence on future total private consumption expenditures cannot be explained by either precautionary savings motive or permanent income hypothesis. The results on nondurable consumption are inconclusive.

The study proceeds as follows: The first section introduces the data. Then, we run estimations to evaluate the significance of consumer confidence indices on future private consumption growth. Following that, we compare the out-of-sample forecast performance of the model specifications with and without consumer confidence indices. Afterward, we test precautionary savings motive and permanent income hypothesis for the link between consumer sentiment and future consumption growth. The last section concludes and addresses future research.

\section{Data}

The data span the period 2002Q1-2014Q4. Private consumption is the dependent variable, while consumer confidence, real stock prices, real interest rate, real labor income, and exchange rate are the independent variables. Consumer sentiment indicators are compiled from two different sentiment surveys of CNBC- $\mathrm{e}^{1}$ and of Turkstat conducted in collaboration with Central Bank of the Republic of Turkey (CBRT). We use overall indices from both surveys and Consumer's Expectations Index (CEI) and Propensity to Consume Index (PCI) from the CNBC-e survey. 
The private consumption data and its subcomponents ${ }^{2}$ are from the 1998-based year GDP series. Real labor income data are our own calculations with the information from the Household Labor Force Survey (HLFS) and Labor Cost Index (LCI). For real stock price index, we deflate nominal stock exchange data from Borsa Istanbul by Consumer Price Index $(2003=100)$. For exchange rate, we use the basket of Euro and US dollar, calculated with equal weights. The increase in the basket means depreciation of the Turkish lira. Finally, we calculate the real interest rate by deflating the nominal Treasury bond rate at the maturity of 2 years by 2 -year-ahead inflation expectations. All monthly data are transformed into quarterly data by taking simple averages of the associated months. Consumption and real labor income data are seasonally adjusted. The source of GDP, HLFS, LCI, and CPI is Turkstat.

An important issue to consider in short-term forecasting studies in the literature is the vintage of the data. Lahiri, Monokroussos, and Zhao (2016) argue that what matters for the analysts and policymakers should be the real-time data as it is the data available at the time of forecasting to the forecaster; and the final vintage of the data regarding the historical values should be avoided. Diron (2008), Giannone, Reichlin, and Small (2008), and Lahiri, Monokroussos, and Zhao (2016) show examples of pseudo real-time and genuine real-time exercises for GDP and consumption forecasts. This is a very valid concern particularly when contemporaneous relationships between the explanatory and dependent variables are imposed in the regressions. However, our empirical setup does not necessitate pursuing any type of real-time exercise in our forecasting analysis. The reason has two folds: First, contrary to the aforementioned nowcasting studies using real-time data we do not use current period values and use only the lagged values of the explanatory variables in the model specifications. Furthermore, unlike US and European countries, there are no flash estimates of GDP in Turkey and all data needed at the time of the forecast in real time had already been available to the forecaster. As shown clearly in the data timeline, when we want to forecast the consumption growth in 2014Q1 after the release of 2013Q4 data in March 31, 2014, the data set we need for 2013Q4 and before were already known (Figure 2). If, as in the nowcasting studies, we had the current period value of the explanatory variables in our specifications, we had to use the most available data as of March 31,2014 for the first quarter of $2014 .^{3}$

One thing we have to decide on is whether to use the first vintage of consumption data instead of the final data, as consumption data is subject to revisions throughout the GDP data release periods.

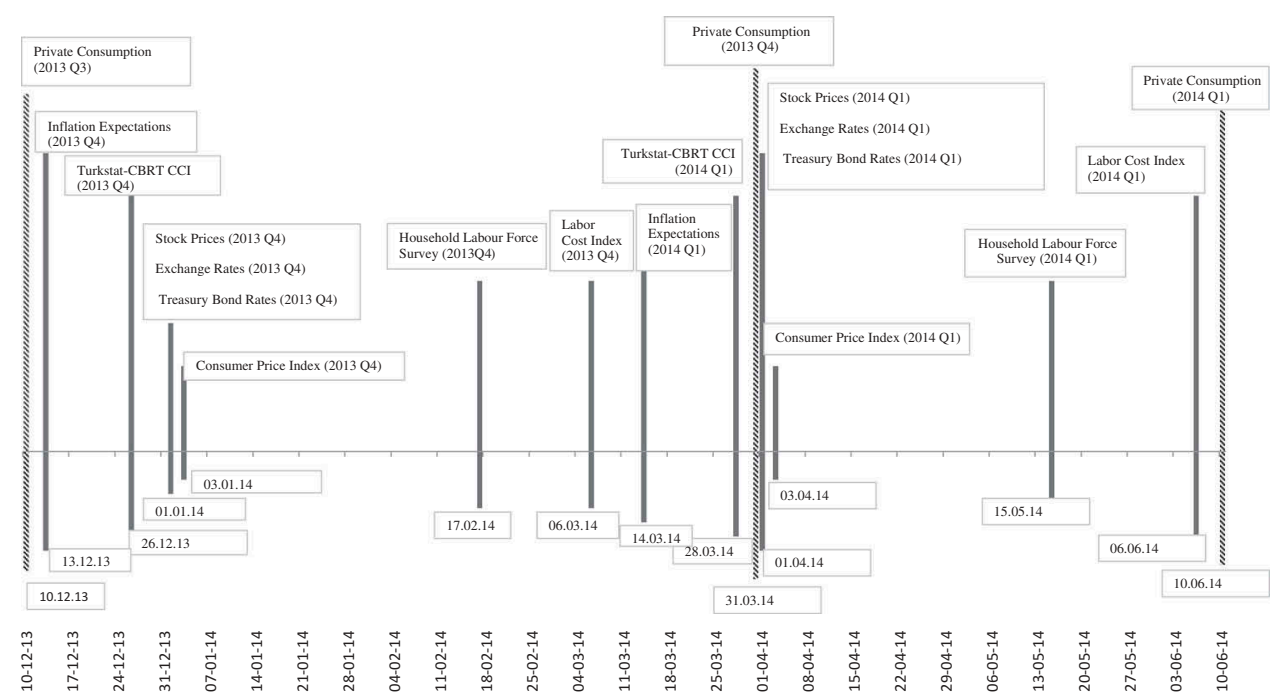

Figure 2. Timeline for data releases. 
Ludvigson (2004) and Croushore (2005) claim that if data revisions are large and systematic, empirical results using the revised data could give biased results. ANOVA test results show that the revision in the level of consumption and its periodical changes have no statistical significance (see Table S1, available online). Thus, biasedness should not be an issue in our estimations when we use the revised consumption data in our analyses.

\section{Empirical Analysis}

This section seeks answers to the following two questions: (i) "Does consumer confidence provide information about future private consumption growth?" (ii) "Does consumer confidence provide unique information about future private consumption growth?" We carry out estimations not only for total private consumption but also for the proxies we calculate for durable and nondurable consumption. The reason is that discretionary purchases can be postponed for a particular time when sentiment deteriorates and such purchases mostly contain purchases of homes, vehicles, and other household durable goods. Aggregation of consumption items may hinder the role of consumer sentiment on future private consumption growth. We follow a two-step procedure in our empirical analysis. We start with estimating a basic benchmark model, which (a type of) quarterly private consumption growth is regressed only on its own lags (Equation 1). Next, we add the lagged values of (a measure of) consumer confidence to this basic specification (Equation 2). Here, the aim is to compare in-sample forecast performance of the models with and without consumer confidence indicators. If coefficient estimates for consumer confidence indices are statistically significant and adjusted $\mathrm{R}^{2}$ increases after adding consumer confidence measures, then we conclude that lagged values of consumer sentiment have predictive power for private consumption growth.

$$
\begin{gathered}
\Delta \log C_{t}=\alpha_{0}+\sum_{i=1}^{k} \beta_{i} \Delta \log C_{t-i}+\varepsilon_{t} \\
\Delta \log C_{t}=\alpha_{0}+\sum_{i=1}^{k} \beta_{i} \Delta \log C_{t-i}+\sum_{i=1}^{m} \gamma_{i} C C C_{t-i}+\varepsilon_{t}
\end{gathered}
$$

We add other indicators, which are believed to play a role on consumption growth, to identify the distinctive information content of consumer confidence on future private consumption growth other than the information already contained in some other economic and financial indicators. To this end, we again follow a two-step procedure. This time, we first determine a benchmark model containing the lags of additional control variables (Equation 3) and then add the lagged values of consumer confidence indicators (Equation 4). If confidence measures are statistically significant and there is an improvement in the adjusted $\mathrm{R}^{2}$ after adding consumer confidence measures, we conclude that consumer confidence provides unique information about future private consumption growth.

$$
\begin{gathered}
\Delta \log \mathrm{C}_{\mathrm{t}}=\alpha_{0}+\sum_{\mathrm{i}=1}^{\mathrm{k}} \beta_{\mathrm{i}} \Delta \log \mathrm{C}_{\mathrm{t}-\mathrm{i}}+\sum_{\mathrm{i}=1}^{\mathrm{n}} \delta_{\mathrm{i}} \mathrm{S}_{\mathrm{t}-\mathrm{i}}+\varepsilon_{\mathrm{t}} \\
\Delta \log \mathrm{C}_{\mathrm{t}}=\alpha_{0}+\sum_{\mathrm{i}=1}^{\mathrm{k}} \beta_{\mathrm{i}} \Delta \log \mathrm{C}_{\mathrm{t}-\mathrm{i}}+\sum_{\mathrm{i}=1}^{\mathrm{n}} \delta_{\mathrm{i}} \mathrm{S}_{\mathrm{t}-\mathrm{i}}+\sum_{\mathrm{i}=1}^{\mathrm{m}} \gamma_{\mathrm{i}} \mathrm{CCI}_{\mathrm{t}-\mathrm{i}}+\varepsilon_{\mathrm{t}}
\end{gathered}
$$

Following Bram and Ludvigson (1998), Ludvigson (2004), Croushore (2005), and Lahiri, Monokroussos, and Zhao (2012), we include the change in the logarithm of real stock prices (RSTOCK), the growth rate of real labor income (RLI), the first difference of real interest rate (RINT), and the change in the logarithm of exchange rate basket (EXC), which are represented as 
the vector "S" in Equations 3 and 4. In addition, we insert two dummy variables. The first one (D09Q2) is for 2009Q2, when Turkish government exerted temporary tax reductions for durable goods, particularly for automobiles and home appliances. It is included in regressions for durable consumption and total consumption growth. The second one (DREC) is for the recessionary period during the global financial crisis period and is added to regressions for all consumption indicators.

At this point, two issues need clarification. First, in initial model specifications, we follow the literature and set the number of lags to four. However, as we do not have a long enough data to keep all four lags of each variable, we eliminate statistically insignificant lags of each variable by applying the General to Specific (GETS) method. Therefore, $\mathrm{m}, \mathrm{n}$, and $\mathrm{k}$ values in the equations from 1 to 4 vary across each final model specification. The second issue is about the transformation of consumer confidence indices. Most of the studies in the literature prefer using the levels of consumer confidence indices. Nevertheless, we run the regressions with both terms. ${ }^{4}$

\section{Estimations for Total Private Consumption Growth}

Estimation results for the benchmark model show that own lagged values of total private consumption growth are neither individually nor jointly statistically significant in explaining its current growth (Table 1). This is in sharp contrast to the European and the US private consumption data. Next, we add consumer confidence to the benchmark. As auto regressive components are not statistically significant, total private consumption growth is regressed only on the first four lags of consumer confidence measures. Using GETS, the first two lags of the sentiment indicators are found statistically significant in explaining private consumption growth (Table 2). The incremental predictive power of sentiment indicators in level terms is higher than that of sentiment indicators in change terms. Looking at the adjusted $\mathrm{R}^{2} \mathrm{~s}$, CEI has the highest incremental predictive power across all measures in level terms.

Table 3 reports estimation results after including other control variables. At first, we cannot find a statistically significant coefficient for the sentiment measures. However, once we apply GETS to seek for individual significance, we find that the third lag of $\Delta(\mathrm{CNBC}-\mathrm{e})$ is statistically significant. Thus,

Table 1. Simple benchmark regressions on consumption aggregates.

\begin{tabular}{lcccc}
\hline & Total private consumption & $\begin{array}{c}\text { Durable } \\
\text { consumption }\end{array}$ & $\begin{array}{c}\text { Nondurable } \\
\text { consumption }\end{array}$ & $\begin{array}{c}\text { Nondurable } \\
\text { consumption }\end{array}$ \\
\hline AR $(-1)$ & 0.141 & 0.236 & -0.157 & $-0.206^{*}$ \\
& $(0.84)$ & $(1.36)$ & $(-1.29)$ & $(-1.65)$ \\
AR $(-2)$ & 0.183 & 0.099 & $0.274^{* *}$ & $0.226^{* *}$ \\
& $(1.38)$ & $(0.70)$ & $(2.67)$ & $(2.14)$ \\
AR $(-3)$ & 0.029 & 0.114 & 0.106 & - \\
& $(0.23)$ & $(0.88)$ & $(0.65)$ & - \\
AR $(-4)$ & 0.065 & 0.0807 & -0.147 & - \\
& $(0.43)$ & $(0.68)$ & $(-0.97)$ & \\
D09Q2 & $0.083^{* * *}$ & $0.234^{* * *}$ & - & $0.0086^{* * *}$ \\
& $(5.02)$ & $(6.28)$ & & $(3.51)$ \\
Constant & 0.0037 & 0.001 & $0.0079^{* *}$ & 49 \\
& $(0.68)$ & $(0.11)$ & $(2.61)$ & 0.119 \\
Obs. & 47 & 47 & 47 & 0.081 \\
R $^{2}$ & 0.205 & 0.354 & 0.134 & 0.0134 \\
Adj. R & 0.108 & 0.276 & 0.052 & \\
RMSE & 0.0222 & 0.0427 & 0.0129 &
\end{tabular}

Notes: Dependent variable for each equation is written on top of each column. AR denotes the lag of the dependent variable. t-statistics in parentheses, $* * *, * * *$ show significance at $10 \%, 5 \%, 1 \%$, respectively. 
Table 2. Total private consumption growth estimation results with consumer confidence indices.

\begin{tabular}{lcccccccc}
\hline & CNBC-e & CEI & PCI & CBRT & $\Delta$ (CNBC-e) & $\Delta$ (CEI) & $\Delta($ PCI) & $\Delta($ CBRT $)$ \\
\hline CCI (-1) & $0.00084^{* * *}$ & $0.0011^{* * *}$ & $0.00065^{* * *}$ & $0.0022^{* *}$ & $0.00094^{* * *}$ & $0.00097^{* *}$ & $0.00061^{* * *}$ & $0.0017^{*}$ \\
& $(4.24)$ & $(4.76)$ & $(3.34)$ & $(2.68)$ & $(2.75)$ & $(2.24)$ & $(3.31)$ & $(1.94)$ \\
CCI (-2) & - & - & $-0.00053^{* *}$ & $-0.00153^{*}$ & - & - & - & - \\
& & & $(-2.58)$ & $(-1.81)$ & & & & \\
D09Q2 & $0.087^{* * *}$ & $0.092^{* * *}$ & $0.048^{* * *}$ & $0.073^{* * *}$ & $0.0513^{* * *}$ & $0.050^{* * *}$ & $0.045^{* * *}$ & $0.061^{* * *}$ \\
& $(14.61)$ & $(14.01)$ & $(6.91)$ & $(6.94)$ & $(8.88)$ & $(7.05)$ & $(6.91)$ & $(14.05)$ \\
Constant & $-0.073^{* * *}$ & $-0.089^{* * *}$ & -0.0037 & -0.046 & $0.011^{* * *}$ & $0.011^{* * *}$ & $0.011^{* * *}$ & $0.0079^{* *}$ \\
& $(-3.78)$ & $(-4.28)$ & $(-0.34)$ & $(-1.15)$ & $(3.49)$ & $(3.40)$ & $(3.51)$ & $(2.46)$ \\
Obs. & 51 & 51 & 50 & 42 & 50 & 50 & 50 & 42 \\
R $^{2}$ & 0.413 & 0.469 & 0.308 & 0.342 & 0.316 & 0.277 & 0.283 & 0.287 \\
Adj. R & 0.389 & 0.447 & 0.263 & 0.291 & 0.287 & 0.246 & 0.253 & 0.251 \\
RMSE & 0.0191 & 0.0182 & 0.0212 & 0.0192 & 0.0208 & 0.0214 & 0.0213 & 0.0198
\end{tabular}

Notes: Dependent variable is the total private consumption growth for all equations and CCI denotes the consumer confidence index denoted at the top of each column. $\Delta$ denotes change in the variable. $\mathrm{t}$-statistics in parentheses: *, **, $* * *$ show significance at $10 \%, 5 \%, 1 \%$, respectively.

we conclude that consumer confidence may contain independent information for total private consumption. However, this finding is not strong.

\section{Estimations for Durable and Nondurable Consumption}

Estimation results for durable consumption show that similar to the regressions for total private consumption growth, lags of durable consumption growth are unable to predict its own current growth rate (Table 1), whereas lagged values of consumer confidence do predict (Table 4). CEI has the highest explanatory power among all confidence measures. However, once we control for the other indicators, we do not find any single or joint significance regardless of the type and definition of consumer sentiment (see Table S2, available online). One reason may be the close relation between consumer confidence indices and exchange rate in Turkey, which is well documented in Karasoy (2015) and Gürgür and Kılınç (2015). It is interesting that although PCI is intended to measure durable consumption propensity, it does not provide extra information for future durable consumption growth. This hints that the responses to PCI question is formed by financial conditions, which are thought to affect durable consumption spending and are probably captured by the exchange rate and stock price movements. Another reason may probably be that the propensity of purchasing durable goods is stronger for individuals with higher income, and the sentiment surveys cover individuals from all income levels, which weakens the link between PCI and the durable consumption. Finally, estimations for quarterly nondurable consumption growth show that unlike for total private and durable consumption growth, it has an autoregressive structure (Table 1). Thus, basic benchmark model for nondurable consumption growth contains autoregressive terms of order two. When we add the lagged values of consumer confidence to this benchmark, we again find that consumer confidence has a predictive power on consumption growth (Table 5). Here, again consumer confidence indices in level terms perform better than the differenced indices. Among all measures, the increment in adjusted $\mathrm{R}^{2}$ is the highest for CNBC-e. Estimations of confidence-augmented equations show that CBRT, PCI, and $\Delta$ (PCI) can provide extra information on nondurable consumption growth, while the gain is the highest for PCI (Table 6). This is an interesting finding, as by definition this question is not intended to measure the tendency for nondurable consumption. However, we should note that our proxy for nondurable consumption also covers services sector. As argued by Lahiri, Monokroussos, and Zhao (2016), services expenditures can also be considered as discretionary spending. In addition, the share 


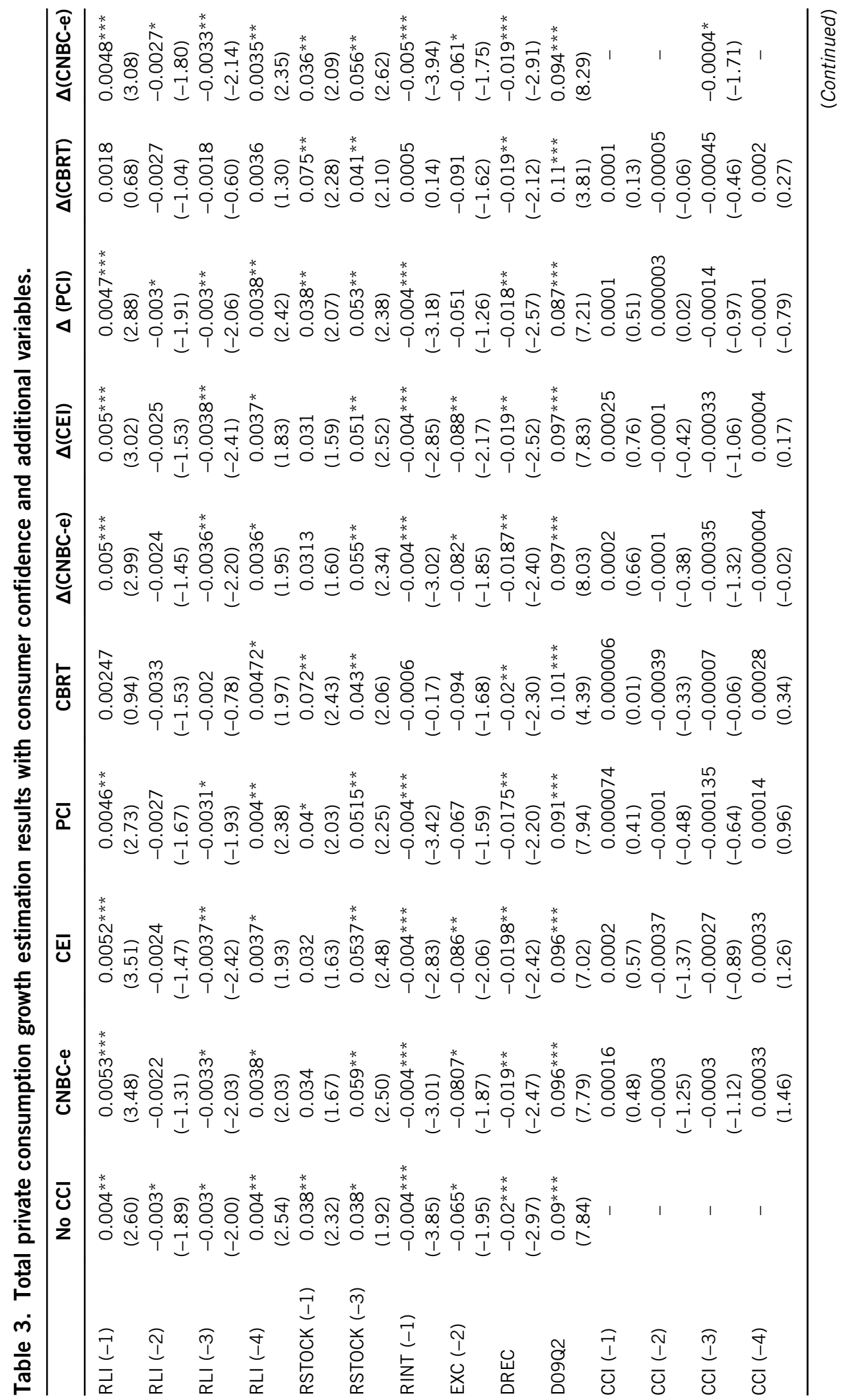




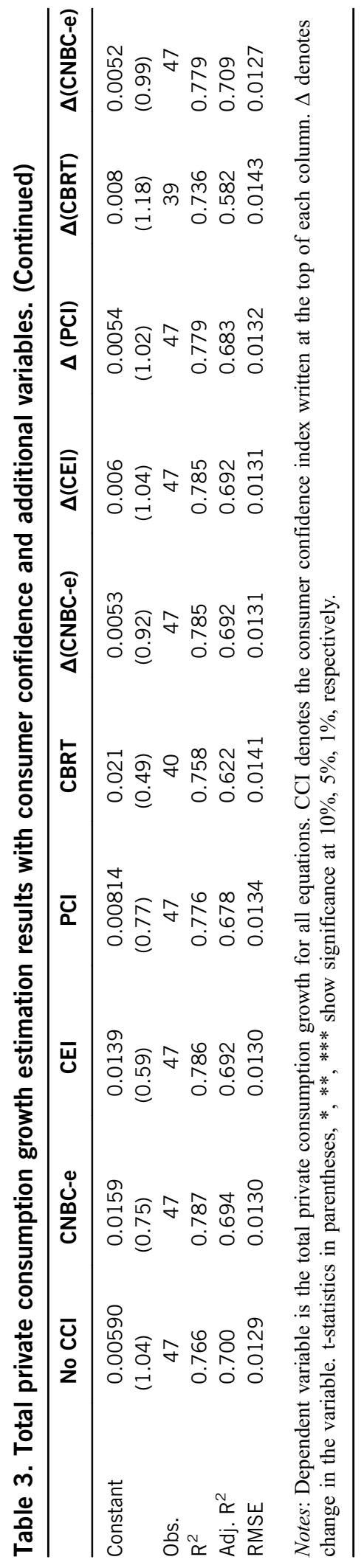


Table 4. Durable consumption growth estimation results regressions with consumer confidence indicators.

\begin{tabular}{lcccccccc}
\hline & CNBC-e & CEI & PCI & CBRT & $\Delta$ (CNBC-e) & $\Delta$ (CEI) & $\Delta(P C I)$ & $\Delta$ (CBRT) \\
\hline CCI (-1) & $0.0014^{* * *}$ & $0.002^{* * *}$ & $0.001^{* * *}$ & $0.004^{* * *}$ & $0.0014^{* *}$ & $0.0013^{*}$ & $0.001^{* * *}$ & $0.0035^{*}$ \\
& $(3.57)$ & $(5.23)$ & $(2.70)$ & $(2.72)$ & $(2.25)$ & $(1.75)$ & $(2.69)$ & $(1.92)$ \\
CCI (-2) & - & - & $-0.0009^{* *}$ & $-0.0031^{*}$ & - & - & - & - \\
& & & $(-2.30)$ & $(-1.84)$ & & & & \\
D09Q2 & $0.226^{* * *}$ & $0.237^{* *}$ & $0.159^{* * *}$ & $0.203^{* * *}$ & $0.169^{* * *}$ & $0.168^{* * *}$ & $0.157^{* * *}$ & $0.182^{* * *}$ \\
& $(18.60)$ & $(22.19)$ & $(12.21)$ & $(9.23)$ & $(17.44)$ & $(14.43)$ & $(13.01)$ & $(21.73)$ \\
Constant & $-0.125^{* * *}$ & $-0.167^{* *}$ & 0.002 & -0.085 & $0.0125^{* *}$ & $0.0126^{* *}$ & $0.013^{* *}$ & 0.006 \\
& $(-3.28)$ & $(-4.91)$ & $(0.10)$ & $(-1.02)$ & $(2.17)$ & $(2.12)$ & $(2.25)$ & $(0.97)$ \\
Obs. & 51 & 51 & 50 & 42 & 50 & 50 & 50 & 42 \\
$\mathrm{R}^{2}$ & 0.475 & 0.556 & 0.386 & 0.471 & 0.379 & 0.348 & 0.382 & 0.437 \\
Adj. R & 0.453 & 0.538 & 0.346 & 0.429 & 0.353 & 0.320 & 0.356 & 0.408 \\
RMSE & 0.0361 & 0.0332 & 0.0398 & 0.0374 & 0.0396 & 0.0406 & 0.0395 & 0.0381
\end{tabular}

Notes: Dependent variable is the durable consumption growth for all equations. CCI denotes the consumer confidence index written at the top of each column. $\Delta$ denotes change in the variable. t-statistics in parentheses, *,**,*** show significance at $10 \%, 5 \%, 1 \%$, respectively.

of services in all expenditures is constantly increasing over time (Curtin 2007; Lahiri, Monokroussos, and Zhao 2016). This makes such expenditures to be sensitive to sentiment changes as well. Thus, although we cannot distinguish services consumption due to data unavailability, our result for nondurables may be considered in harmony with that of Lahiri, Monokroussos, and Zhao (2016), who find that the highest gains from including consumer sentiment in forecasting are observed in services spending equations.

\section{Out-of-Sample Forecast Performance}

This section presents the comparison of out-of-sample forecast performance of the models with and without the lagged values of consumer confidence measures, whose specifications were finalized before. To achieve this, we carry out recursive one-step-ahead forecasts in an expanding window. As Hansen and Timmermann (2012) discuss, there is no standard way of splitting the sample period for the initial parameter estimation and the number of out-of-sample forecasts. We take the first 40 observations for the initial estimation and the remaining 12 observations for the out-of-sample forecast evaluation. As a measure of forecast accuracy, we calculate Root Mean Squared Forecast Errors (RMSFE) for each model. If RMSFE of equations with consumer confidence index is lower (higher) than that of benchmark equation, that is, relative RMSFE takes value lower (higher) than 1, we conclude that consumer confidence measures improve (deteriorate) forecasting future consumption growth. We also test the significance of the differences between RMSFEs by the methodology proposed by Clark and West (2007) for nested models. ${ }^{5}$

Table 7 shows the RMSFEs calculated for each specification with and without consumer sentiment and additional explanatory variables for quarterly total private consumption, durable consumption, and nondurable consumption growth. For total private consumption, when not used in conjunction with other explanatory variables, out-of-sample forecast errors fall with the use of any of the consumer confidence measures, except CNBC-e. However, only PCI, $\triangle(\mathrm{CNBC}-\mathrm{e}), \Delta(\mathrm{CEI})$, and $\Delta(\mathrm{PCI})$ have statistically different out-of-sample performance than that of the benchmark model. On the other hand, when used in conjunction with economic and financial variables, we cannot observe an improvement in out-of-sample forecast performance. Similar to total private consumption growth, some consumer confidence indicators improve the forecasts over the benchmark model for durable goods; however, once explained by other economic and financial variables, adding the lagged values of consumer 


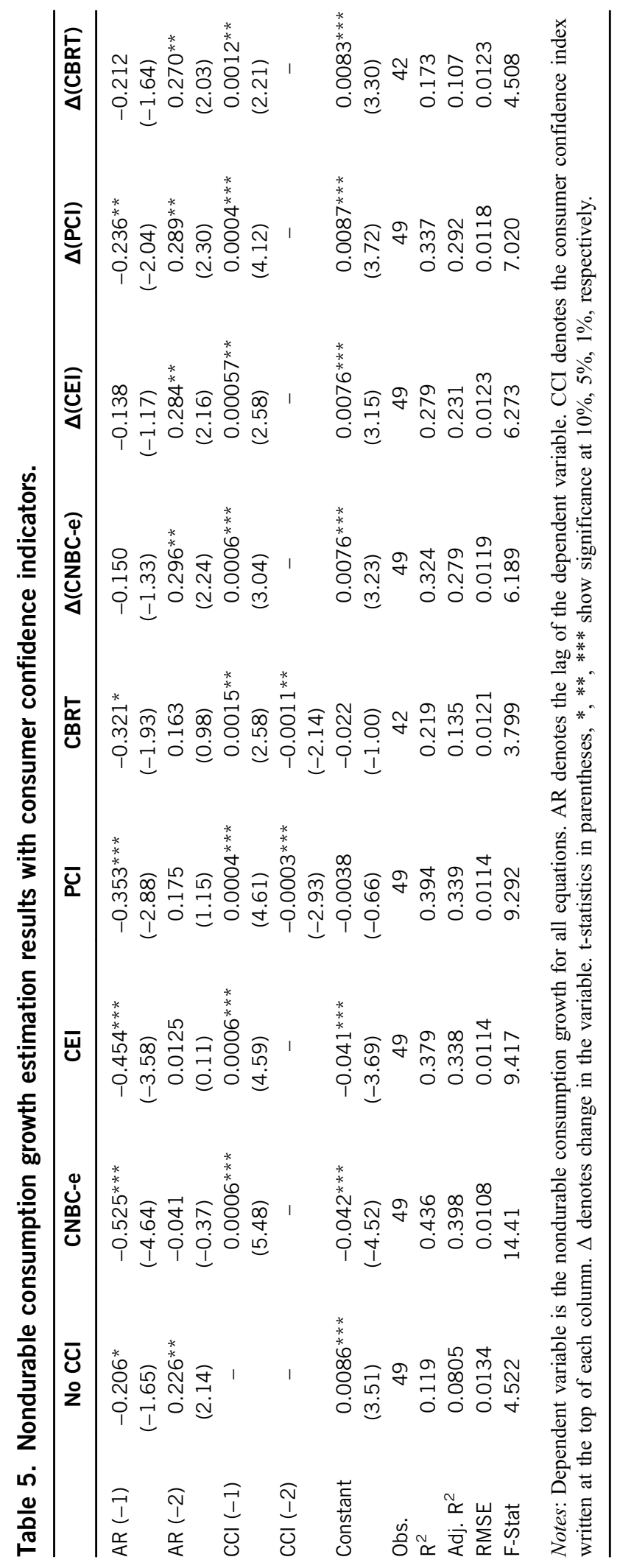




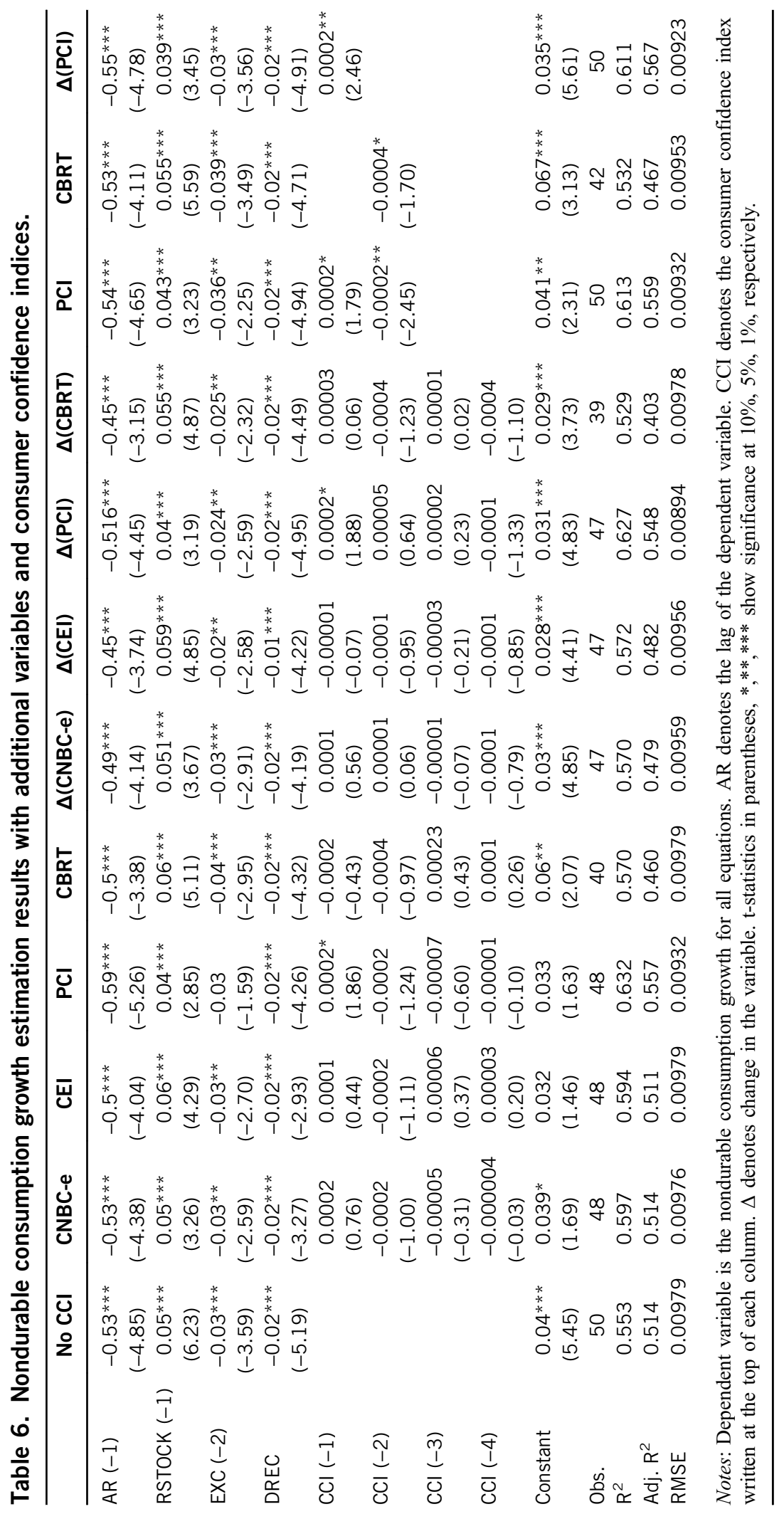




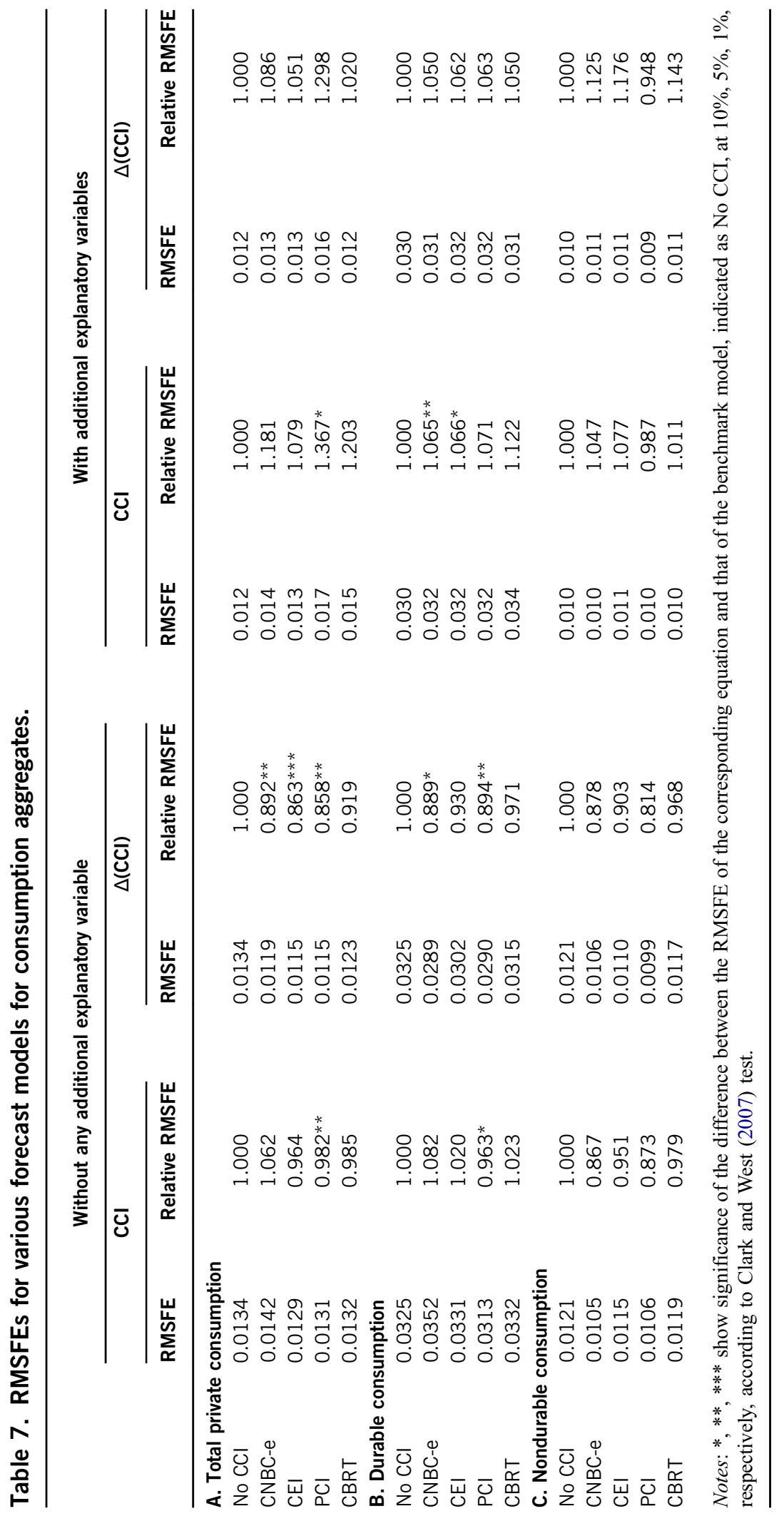


confidence indicators do not improve the out-of-sample forecasts. Finally, consumer confidence measures do not provide statistically significant improvement over benchmark models in predicting nondurable consumption growth either.

\section{Consumer Confidence and Consumption Theories}

In this section, we investigate whether there is a link between the predictive power of consumer confidence indices on future private consumption growth and what consumption theories suggest it to be. Carroll, Fuhrer, and Wilcox (1994), Souleles (2004), Ludvigson (2004), Lahiri, Monokroussos, and Zhao (2012), and Cuenca, Flores, and Morales (2013) examine whether precautionary savings motive (PSM) or the permanent income hypothesis (PIH) are capable of explaining their results. While none of them could find an evidence to support the validity of PIH in explaining predictive power of consumer confidence on future consumption changes, only Souleles (2004) and Cuenca, Flores, and Morales (2013) confirmed the existence of PSM for the US and Peru, respectively.

From a simple PSM perspective, if we consider consumer confidence as a measure of uncertainty, a negative shock to consumer sentiment in the previous period would mean increasing level of uncertainty and more precautionary savings at the same period. As a result, consumption level falls with the rising uncertainty. Accordingly, in the subsequent period, consumption growth rate will be higher because consumption level in the previous period is lower than that it would have been in the absence of negative confidence shock (Carroll, Fuhrer, and Wilcox 1994). However, as depicted in the estimations, we rather find a positive relationship between consumer sentiment in the previous period and consumption growth today in almost all estimations. Therefore, we cannot interpret the role of consumer sentiment on predicting future consumption growth by a simple PSM perspective.

As an alternative, the PIH may explain the role of consumer confidence on predicting future consumption growth. Recall that, consumption can only change as a consequence of unexpected changes in permanent income according to the PIH. Therefore, if the PIH holds, consumer sentiment can influence future consumption expenditures only indirectly through its predictive power on future real labor income (Lahiri, Monokroussos, and Zhao 2012). Ludvigson (2004) tests the possibility of that channel by regressing labor income growth on its own lags and the lags of confidence measures. She shows that the lags of consumer confidence are jointly statistically significant and has explanatory power for labor income growth. We reach the same conclusion for Turkey, except for the case PCI is used (see Table S3, available online). However, this does not confirm that consumer sentiment affects future consumption growth only indirectly as the PIH states. Carroll, Fuhrer, and Wilcox (1994), Ludvigson (2004), and Lahiri, Monokroussos, and Zhao (2012) apply a two-step procedure to solve out this issue. In the first step, labor income growth is regressed on the lagged values of consumption and the other available indicators introduced in the previous sections. Later, in the second step, consumption growth is regressed on predicted value of labor income growth from the first step and the lagged values of consumer sentiment measures. If consumer sentiment measures are found statistically significant in the second step, consumer sentiment has also direct effects on future consumption growth, which contradicts PIH.

Below, we present the results of this two-step analysis for total and nondurable consumption with the consumer sentiment measures, which have been found to provide unique information for the said consumption indicators in the previous sections. Recall that for durable consumption we find that consumer sentiment provides no marginal information for future expenditures. For this reason, we do not run regressions for durable consumption in this section.

Table 8 shows that for total consumption, the first lag of CNBC is statistically significant, indicating that consumer confidence affects consumption not only through its indirect effects on real labor income growth, but also directly. For the nondurable consumption, the results are mixed. While the lags of PCI are significant, no significance is found when CBRT is used. Therefore, we find that PIH is not sufficient to explain the predictive power of consumer sentiment measures on total consumption in Turkey. For nondurable consumption, the result is ambiguous, because it depends on the definition of the consumer sentiment. 
Table 8. Consumption growth estimation results for testing permanent income hypothesis.

\begin{tabular}{|c|c|c|c|}
\hline & \multirow{2}{*}{$\frac{\text { Total consumption }}{\text { CNBC-e }}$} & \multicolumn{2}{|c|}{ Nondurable consumption } \\
\hline & & $\mathrm{PCl}$ & CBRT \\
\hline \multirow[t]{2}{*}{ Predicted RLI } & 0.004 & 0.0017 & 0.0032 \\
\hline & $(1.57)$ & $(1.01)$ & $(1.41)$ \\
\hline \multirow[t]{2}{*}{$\operatorname{CCl}(-1)$} & $0.0007^{* * *}$ & $0.00034^{* * *}$ & 0.0004 \\
\hline & $(2.79)$ & $(3.05)$ & $(0.65)$ \\
\hline \multirow[t]{2}{*}{$\mathrm{CCl}(-2)$} & -0.0003 & $-0.0004^{* *}$ & -0.001 \\
\hline & $(-0.96)$ & $(-2.46)$ & $(-1.63)$ \\
\hline \multirow[t]{2}{*}{$\mathrm{CCl}(-3)$} & -0.00013 & 0.0002 & 0.0009 \\
\hline & $(-0.46)$ & $(1.31)$ & $(1.22)$ \\
\hline \multirow[t]{2}{*}{$\mathrm{CCl}(-4)$} & -0.0001 & -0.00008 & -0.00005 \\
\hline & $(-0.42)$ & $(-0.74)$ & $(-0.09)$ \\
\hline D09Q2 & $\begin{array}{l}0.085^{* * *} \\
(4.35)\end{array}$ & - & - \\
\hline \multirow[t]{2}{*}{ DREC } & -0.0147 & -0.0066 & -0.0034 \\
\hline & $(-1.62)$ & $(-1.15)$ & $(-0.49)$ \\
\hline \multirow[t]{2}{*}{ Constant } & -0.0158 & -0.0017 & -0.0026 \\
\hline & $(-0.68)$ & $(-0.20)$ & $(-0.10)$ \\
\hline Obs. & 47 & 47 & 40 \\
\hline $\mathrm{R}^{2}$ & 0.567 & 0.356 & 0.231 \\
\hline Adj. $R^{2}$ & 0.489 & 0.259 & 0.0909 \\
\hline RMSE & 0.0168 & 0.0114 & 0.0127 \\
\hline
\end{tabular}

\section{Conclusion}

In this study, we have investigated the role of consumer confidence indices on explaining and forecasting future quarterly consumption growth in Turkey. We have shown that the lagged values of consumer confidence indices have explanatory power on the future growth of total private consumption and its subcomponents under the absence of other related indicators for consumption. However, once other economic and financial variables, which are believed to play a role on consumption growth, are included in the models, the predictive power either decreases or vanishes. CNBC-e for total consumption growth, and CBRT and PCI for nondurable consumption growth maintain their predictive power even after controlling for other indicators. Therefore, one can conclude that consumer confidence may provide unique information for consumption growth depending on which definition of consumer sentiment is used. Moreover, our results regarding consumer confidence indices' role on improving out-of-sample forecasting power do not differentiate significantly from the results of in-sample estimations, although there are some minor differences. Finally, our results do not support the implications of permanent income hypothesis and precautionary savings motive for the role of consumer sentiment on future total consumption growth. It is inconclusive for the nondurable consumption. Our findings are in accordance with most of the studies in the literature, which signifies that specifically the financial variables embeds most of the information consumer confidence provides for future consumption growth.

The methodology we employ and our findings are not new for the US or advanced economies; however, still it contributes to the Turkish literature as it is the first study to assess the role of consumer sentiment on consumption. In this regard, this study will be a benchmark to the further studies and help the literature on this issue in Turkey to progress in a similar fashion to the developed countries. It also adds to the limited literature in the developing countries. 
We should note that the data unavailability have restricted the scope of the empirical analysis. First, monthly sentiment data would have been more informative about consumption changes than using the quarterly averages, if they were available. Second, it would have been more preferable to analyze durable goods, nondurable goods, and services, separately similar to Lahiri, Monokroussos, and Zhao (2016). Third, as more consumer sentiment data accumulates, the opportunities to study further topics will increase. For instance, estimation methods such as vector autoregression (VAR) may be utilized to incorporate simultaneous relations between the variables and to allow identifying the dynamics of an impact of a confidence shock to other macroeconomic variables (Dees and Brinca 2013; Leeper 1992). Further research could also investigate the existence of confidence channel, which aims to identify the spillover effects of shocks in international economies to domestic economies through deteriorated consumer confidence (Avery and Zemsky 1998; Dees and Brinca 2013). On the other hand, threshold analysis would be beneficial to understand how large the confidence shock should be to bring extra information beyond other available indicators. It is also possible that the movements in consumer confidence may not be fully explained by economic and financial variables (Fuhrer 1993). Further studies may investigate in detail the other factors that influence consumer confidence, such as psychological factors or political environment (Ramalho, Caleiro, and Dionfsio 2011). As shown by Yüncüler (2016) for Turkey, the sub questions forming consumer confidence indices may have different implications for the consumption decisions, and accordingly, can also be used separately instead of overall indices. Finally, augmenting a wider set of explanatory variables that are relevant to consumption spending may be another option by applying dynamic factor modeling as in Lahiri, Monokroussos, and Zhao (2016). ${ }^{5}$

\section{Supplemental Materials}

Supplemental data for this article can be accessed on the publisher's website.

\section{Notes}

1. It has been renamed as Bloomberg HT in October 2015.

2. TURKSTAT does not publish nondurable or durable consumption under 1998-based GDP data. However from private consumption data under COICOP classification, we calculate proxy series for durable and nondurable consumption. We summed up furniture and household appliances, transport and communication, and recreation and culture sub-items to yield a proxy for durable consumption. The rest of the private consumption is considered as nondurable consumption. Note that nondurable consumption is a proxy for the sum of semi durable goods, nondurable goods, and services expenditures. It is impossible to separate further goods and services expenditures under this setting.

3. In fact, Diron (2008) shows that using real-time data may not improve the forecasts compared to using revised data either.

4. According to ADF test all the variables except CNBC-e, CBRT, and CEI are found to be I(1). We also performed cointegration tests to every specification to be estimated but cointegration is rejected in almost all cases. Therefore, we cannot specify the models with levels of the variables other than consumer confidence measures. Among the sentiment indicators, $\mathrm{PCI}$ is found to be $\mathrm{I}(1)$ and might necessitate to be differenced to be stationary. However, as the statistical significance level of the test is very close to $10 \%$, we think that using PCI in levels will not create a big problem in assessing the estimation results.

5. We did not use Diebold-Mariano Test as it does not perform well in small samples and should not be used when competing models are nested (Diebold 2015).

\section{References}

Avery, C., and P. Zemsky. 1998. Multidimensional uncertainty and herd behavior in financial markets. American Economic Review 88 (4):724-48.

Bram, J., and S. Ludvigson. 1998. Does Consumer Confidence Forecast Household Expenditure? A Sentiment Index Horse Race. Economic Policy Review 4 (2):59-78.

Carroll, C. D., J. C. Fuhrer, and D. W. Wilcox. 1994. Does consumer sentiment forecast household spending? If so, why? The American Economic Review 84 (5):1397-408. 
Çelik, S. 2010. An unconventional analysis of consumer confidence index for the turkish economy. International Journal of Economics and Finance Studies 2 (1):121-29.

Çelik, S., E. Aslanoğlu, and S. Uzun. 2010. The relationship between consumer confidence and financial market: Variables in Turkey during the global crisis.Topics in Middle Eastern and North African Economies 12. https://ecommons.luc.edu/meea/134/

Ceritoğlu, E. 2013. Household expectations and household consumption expenditures: The case of Turkey. Research and Monetary Policy Department Working Paper Series, no. 1310. Ankara, Turkey: Central Bank of Republic of Turkey.

Clark, T. E., and K. D. West. 2007. Approximately normal tests for equal predictive accuracy in nested models. Journal of Econometrics 138 (1):291-311. doi:10.1016/j.jeconom.2006.05.023.

Croushore, D. 2005. Do consumer-confidence indexes help forecast consumer spending in real time? The North American Journal of Economics and Finance 16 (3):435-50. doi:10.1016/j.najef.2005.05.002.

Cuenca, L., J. Flores, and D. Morales. 2013. The consumer confidence index and short-term private consumption forecasting in Peru. Banco Central de Reserva del Perú, no. 2013-004.

Curtin, R. 2007. Consumer sentiment surveys: Worldwide review and assessment. Journal of Business Cycle Measurement and Analysis 2007 (1):7. doi:10.1787/jbcma-v2007-art2-en.

Dees, S., and P. S. Brinca. 2013. Consumer confidence as a predictor of consumption spending: Evidence for the United States and the Euro Area. International Economics 134:1-14. doi:10.1016/j.inteco.2013.05.001.

Diebold, F. X. 2015. Comparing predictive accuracy, twenty years later: A personal perspective on the use and abuse of dieboldmariano tests. Journal of Business \& Economic Statistics 33 (1):1-1. doi:10.1080/07350015.2014.983236.

Dion, D. 2006. Does consumer confidence forecast household spending? The euro area case. Germany: University Library of Munich.

Diron, M. 2008. Short-term forecasts of euro area real GDP growth: An assessment of real-time performance based on vintage data. Journal of Forecasting 27 (5):371-90. doi:10.1002/for.v27:5.

Fuhrer, J. C. 1993. What role does consumer sentiment play in the US macroeconomy? New England Economic Review (JanFeb):32-44.

Giannone, D., L. Reichlin, and D. Small. 2008. Nowcasting: The real-time informational content of macroeconomic data. Journal of Monetary Economics 55 (4):665-76. doi:10.1016/j.jmoneco.2008.05.010.

Golinelli, R., and G. Parigi. 2004. Consumer sentiment and economic activity. Journal of Business Cycle Measurement and Analysis 2004 (2):147-70. doi:10.1787/jbcma-v2004-art10-en.

Görmüş, Ş., and S. Güneş. 2010. Consumer confidence, stock prices and exchange rates: The case of turkey. Applied Econometrics and International Development 10 (2):103-114.

Gürgür, T., and Z. Kılınç. 2015. What drives the consumer confidence in Turkey? No. 1517. Research and Monetary Policy Department, Central Bank of the Republic of Turkey.

Hansen, P. R., and A. Timmermann. 2012. Choice of sample split in out-of-sample forecast evaluation. Economics Working Papers, ECO2012/10, European University Institute.

Howrey, E. P. 2001. The predictive power of the index of consumer sentiment. Brookings Papers on Economic Activity 2001 (1):175-207. doi:10.1353/eca.2001.0010.

Kandır, S. Y. 2006. Tüketici güveni ve hisse senedi getirileri ilişkisi: Imkb mali sektör şirketleri üzerinde bir uygulama. Çukurova Üniversitesi Sosyal Bilimler Enstitüsü Dergisi 15 (2).

Karasoy, H. G. 2015. Consumer confidence indices and financial volatility." no. 1516. Research and Monetary Policy Department, Central Bank of the Republic of Turkey.

Lahiri, K., G. Monokroussos, and Y. Zhao. 2012. Forecasting consumption in real time: The role of consumer confidence surveys. No. 12-02. University at Albany, SUNY, Department of Economics.

Lahiri, K., G. Monokroussos, and Y. Zhao. 2016. Forecasting consumption: The role of consumer confidence in real time with many predictors. Journal of Applied Econometrics 31 (7):1254-75. doi:10.1002/jae.2494.

Leeper, E. M. 1992. Consumer attitudes: King for a day. Economic Review-Federal Reserve Bank of Atlanta 77 (4):1.

Ludvigson, S. C. 2004. Consumer confidence and consumer spending. The Journal of Economic Perspectives 18 (2):29-50. doi:10.1257/0895330041371222.

Mishkin, F. S., R. Hall, J. Shoven, T. Juster, and M. Lovell. 1978. Consumer sentiment and spending on durable goods. Brookings Papers on Economic Activity 1978 (1):217-32. doi:10.2307/2534366.

Mueller, E. 1963. Ten years of consumer attitude surveys: Their forecasting record. Journal of the American Statistical Association 58 (304):899-917. doi:10.1080/01621459.1963.10480677.

Ramalho, E. A., A. Caleiro, and A. Dionfsio. 2011. Explaining consumer confidence in Portugal. Journal of Economic Psychology 32 (1):25-32. doi:10.1016/j.joep.2010.10.004.

Souleles, N. S. 2004. Expectations, heterogeneous forecast errors, and consumption: Micro evidence from the michigan consumer sentiment surveys. Journal of Money Credit and Banking 36 (1):39-72. doi:10.1353/mcb.2004.0007.

Yüncüler, Ç. 2016. Son dönemde tüketici güven endeksleri tüketim göstergeleriyle ne kadar uyumlu? No. 1603. Research and Monetary Policy Department, Central Bank of the Republic of Turkey. 